Annuaire suisse de politique de développement

$21 \mid 2002$

Agriculture suisse et mondialisation

\title{
Liste des pays bénéficiaires de l'aide établie par le
} CAD

\section{(2) OpenEdition \\ Journals}

Édition électronique

URL : http://journals.openedition.org/aspd/961

DOI : $10.4000 /$ aspd.961

ISSN : 1663-9669

Éditeur

Institut de hautes études internationales et du développement

Édition imprimée

Date de publication : 1 avril 2002

Pagination : 429-432

ISSN : 1660-5934

Référence électronique

"Liste des pays bénéficiaires de l'aide établie par le CAD », Annuaire suisse de politique de développement [En ligne], 21 | 2002, mis en ligne le 07 septembre 2012, consulté le 07 septembre 2020. URL : http://journals.openedition.org/aspd/961 ; DOI : https://doi.org/10.4000/aspd.961 


\section{LISTE DES PAYS BÉNÉFICIAIRES DE L'AIDE ÉTABLIE PAR LE CAD POUR LES APPORTS DE RESSOURCES 1997-1998-1999}

\section{PARTIE I: PAYS ET TERRITOIRES EN DÉVELOPPEMENT (AIDE PUBLIQUE AU DÉVELOPPEMENT)}

PMA - Pays les moins avancés

Afghanistan

Angola

Bangladesh

Bénin

Bhoutan

Burkina Faso

Burundi

Cambodge

Cap-Vert

Centrafricaine, Rép.

Comores

Congo, Rép. démocratique

Djibouti

Erythrée

Ethiopie

Gambie
Guinée

Guinée-Bissau

Guinée équatoriale

Haïti

Kiribati

Laos

Lesotho

Liberia

Madagascar

Malawi

Maldives

Mali

Mauritanie

Mozambique

Myanmar

Népal
Niger

Ouganda

Rwanda

Salomon, îles

Samoa occidentales

Sao Tomé et Principe

Sierra Leone

Somalie

Soudan

Tanzanie

Tchad

Togo

Tuvalu

Vanuatu

Yémen

Zambie

Autres PFR - Pays à faible revenu (PNB par habitant <765 dollars en 1995)

${ }^{*}$ Albanie

*Arménie

*Géorgie

Nicaragua

Ghana

Nigeria

*Azerbaïdjan

Guyana

Pakistan

Bosnie-Herzégovine

Honduras

Sénégal

Cameroun

Inde

Sri Lanka

Chine

Kenya

*Tadjikistan

Congo, Rép.

*Kirghize, Rép.

Vietnam

Côte d'Ivoire

Mongolie

Zimbabwe

PRITI - Pays à revenu intermédiaire tranche inférieure (PNB par habitant 766-3035 dollars en 1995)

Algérie

Belize

Irak

Iran

Paraguay

Bolivie

Jamaïque

Pérou

Botswana

Jordanie

Philippines

Colombie

*Kazakstan

St-Vincent et Grenadines

Corée, Rép. démocratique

Liban

Suriname

Costa Rica

Macédoine (ex-Rép. yougoslave)

Swaziland

Cuba

Dominicaine, Rép.

Maroc

Marshall, îles

Dominique

Egypte

El Salvador

Micronésie, Etats fédéraux

${ }^{*}$ Moldavie ${ }^{\prime}$

Syrie

Thaillande

+Timor

Namibie

+Tokelau

Tonga

Niue

Equateur

*Ouzbékistan

Tunisie

Fidji

Grenade

Guatemala

Palaos, îles

*Turkménistan

Turquie

Panama

Venezuela

Indonésie

Papouasie-Nouvelle-Guinée

+ Wallis et Futuna

Yougoslavie, Rép. féd.

Zones sous administration palestinienne

* Pays d'Europe centrale et orientale (PECO) / Communauté des Etats indépendants (CEI).

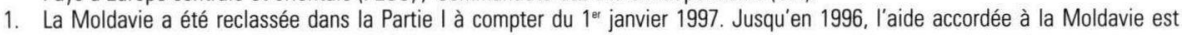
comprise dans I'Aide publique aux PECO/CEl.

+ Territoires. 
PRITS - Pays à revenu intermédiaire tranche supérieure (PNB par habitant 3036-9385 dollars en 1995)

Afrique du Sud

+ Anguilla

Antigua-et-Barbuda

Arabie saoudite

Argentine

Bahrein

Barbade

Brésil

Chili

Cook, îles
Croatie

Gabon

Lybie'

Malaisie

Malte

Maurice

+ Mayotte

Mexique

+ Montserrat

Nauru
Oman

Seychelles

Slovénie

+ Ste-Hélène

St Kitts et Nevis

Ste-Lucie

Trinité-et-Tobago

+ Turks et Caïques, îles

Uruguay

PRE - Pays à revenu élevé (PNB par habitant > 9385 dollars en 1995)

+ Antilles néerlandaises'

+ Gibraltar ${ }^{1}$

+ Aruba $^{1}$

+ Macao ${ }^{1}$

Corée, Rép.'

Mariannes du Nord

+ Nouvelle-Calédonie ${ }^{1}$

+ Polynésie française

+ Vierges, îles (RU)'

\section{PARTIE II: PAYS ET TERRITOIRES EN TRANSITION (AIDE PUBLIQUE)}

$\begin{array}{lll}\text { PECO / CEl (Pays d'Europe centrale et orientale / Communauté des Etats indépendants) } \\ \text { *Bélarus } & { }^{*} \text { *ettonie } & \text { République tchèque } \\ \text { *Bulgarie } & { }^{*} \text { Rituanie } & { }^{*} \text { Rumanie } \\ { }^{*} \text { Estonie } & { }^{*} \text { Pologne } & { }^{*} \text { Ukraine }\end{array}$

\section{Pays et territoires en développement plus avancés ${ }^{2}$}

Bahamas

+ Bermudes

Brunei

+ Caïmans, îles
Chypre

Emirats arabes unis

+ Falkland, îles

+ Hong-Kong, Chine
Israël

Koweït

Qatar

Singapour

Taipei chinois

Remarque: Selon la politique adoptée par le CAD en 1993, la liste des bénéficiaires de l'aide établie par le CAD est composé de deux parties. Les examens périodiques, suivant des critères établis, peuvent conduire au fait que certains pays bénéficiaires soient transférés d'une partie à une autre, notamment de la Partie I à la Partie II (voir le rapport Coopération pour le développement, 1996, p. A101).

Les statistiques qui figurent dans ce rapport incluent les dernières données pour l'année 1996, et reflètent ainsi la liste du CAD telle qu'elle était en 1996. La liste présentée ci-dessus prend effet à partir du $1^{\text {tr }}$ janvier 1997. Les notes cidessus expliquent entre autres les différences entre les listes en 1996 et en 1997.

Source: OCDE, Les dossiers du CAD, Coopération pour le développement, développement international, rapport 1999, 2000, vol. I, p. 289 .

www.oecd.org/dac/htm/daclst97.htm.

1. Tous ces pays et territoires seront reclassés parmi les pays plus avancés le $1^{\text {er }}$ janvier 2000 , à moins qu'une exception soit décidée.

2. Les pays bénéficiaires indiqués en italique figuraient sur la Partie I de la Liste du CAD jusqu'à la fin de 1996. Jusqu'en 1996, l'aide accordée à ces pays est comprise dans I'Aide publique au développement aux Pays à revenu élevé. Ils ont été reclassés dans la Partie II le 1"er janvier 1997. Les autre pays bénéficiaires qui figurent dans ce tableau ont été reclassés dans la Partie Il à compter du $1^{\text {er }}$ janvier 1996. Jusqu'en 1995, I'aide accordée à ces pays est comprise dans l'Aide publique au développement aux Pays à revenu élevé

+ Territoires.

* Pays d'Europe centrale et orientale (PECO) / Communauté des Etats indépendants (CEI). 
PARTIE I: PAYS ET TERRITOIRES EN dÉVELOPPEMENT (AIDE PUBLIQUE AU dÉVELOPPEMENT)

$\begin{array}{lll}\text { PMA - Pays les moins avancés } & & \\ \text { Afghanistan } & \text { Guinée } & \text { Niger } \\ \text { Angola } & \text { Guinée-Bissau } & \text { Ouganda } \\ \text { Bangladesh } & \text { Guinée équatoriale } & \text { Rwanda } \\ \text { Bénin } & \text { Haïti } & \text { Salomon, îles } \\ \text { Bhoutan } & \text { Kiribati } & \text { Samoa occidentales } \\ \text { Burkina Faso } & \text { Laos } & \text { Sao Tomé et Principe } \\ \text { Burundi } & \text { Lesotho } & \text { Sierra Leone } \\ \text { Cambodge } & \text { Liberia } & \text { Somalie } \\ \text { Cap-Vert } & \text { Madagascar } & \text { Soudan } \\ \text { Centrafricaine, Rép. } & \text { Malawi } & \text { Tanzanie } \\ \text { Comores } & \text { Maldives } & \text { Tchad } \\ \text { Congo, Rép. démocratique } & \text { Mali } & \text { Togo } \\ \text { Djibouti } & \text { Mauritanie } & \text { Tuvalu } \\ \text { Erythrée } & \text { Mozambique } & \text { Vanuatu } \\ \text { Ethiopie } & \text { Myanmar } & \text { Yémen } \\ \text { Gambie } & \text { Népal } & \text { Zambie }\end{array}$

$\begin{array}{lll}\text { Autres PFR - Pays à faible revenu (PNB par habitant < } \mathbf{7 6 0} \text { dollars en 1998) } \\ \text { Honduras } & \text { Nigeria } \\ { }^{*} \text { Arménie } & \text { Inde } & \text { Pakistan } \\ { }^{*} \text { Azerbaïdjan } & \text { Indonésie } & \text { Sénégal } \\ \text { Cameroun } & \text { Kenya } & { }^{*} \text { Tadjikistan } \\ \text { Chine } & { }^{*} \text { Kirghize, Rép. } & + \text { Timor oriental } \\ \text { Congo, Rép. } & { }^{*} \text { Moldavie } & { }^{*} \text { Turkmenistan } \\ \text { Corée, Rép. dém. } & \text { Mongolie } & \text { Vietnam } \\ \text { Côte d'Ivoire } & \text { Nicaragua } & \text { Zimbabwe } \\ \text { Ghana } & & \end{array}$

PRITI - Pays à revenu intermédiaire tranche inférieure (PNB par habitant 761-3030 dollars en 1998)

Afrique du Sud

${ }^{*}$ Albanie

Algérie

Belize

Bolivie

Bosnie-Herzégovine

Colombie

Costa Rica

Cuba

Dominicaine, Rép.

Dominique

Egypte

El Salvador

Equateur

Fidji
*Géorgie

Guatemala

Guyane

Irak

Iran

Jamaïque

Jordanie

*Kazakstan

Macédoine (ex-Rép. yougoslave)

Maroc

Marshall, îles

Micronésie, Etats fédéraux

Namibie

Niue

*Ouzbékistan
Papouasie-N"1"-Guinée

Paraguay

Pérou

Philippines

Sri Lanka

St-Vincent et Grenadines

Suriname

Swaziland

Syrie

Thaillande

+ Tokelau

Tonga

Tunisie

+ Wallis et Futuna

Yougoslavie, Rép. féd.

Zones sous administration palestinienne

* Pays d'Europe centrale et orientale (PECO) / Communauté des Etats indépendants (CEI).

+ Territoires.

1. Le Sénégal est devenu un PMA en 2001. 
PRITS - Pays à revenu intermédiaire tranche supérieure (PNB par habitant 3031-9360 dollars en 1998)

$\begin{array}{ll}\text { + Anguilla } & \text { Gabon } \\ \text { Antigua-et-Barbuda } & \text { Grenade } \\ \text { Arabie saoudite } & \text { Liban } \\ \text { Argentine } & \text { Malaisie } \\ \text { Bahrein } & \text { Maurice } \\ \text { Barbade } & + \text { Mayotte } \\ \text { Botswana } & \text { Mexique } \\ \text { Brésil } & + \text { Montserrat } \\ \text { Chili } & \text { Nauru } \\ \text { Cook, îles } & \text { Oman } \\ \text { Croatie } & \text { Palaos, îles }\end{array}$

Panama

+ Ste-Hélène

Ste-Lucie

St Kitts et Nevis

Seychelles

Trinité-et-Tobago

+ Turks et Caïques, îles

Turquie

Uruguay

Venezuela

PRE - Pays à revenu élevé (PNB par habitant > 9360 dollars en 1998) ${ }^{2}$

Malte

Slovénie

\section{PARTIE II: PAYS ET TERRITOIRES EN TRANSITION (AIDE PUBLIOUE)}

$\begin{array}{lll}\text { PECO / CEl (Pays d'Europe centrale et orientale / Communauté des Etats indépendants) } \\ \text { *Bélarus } & { }^{*} \text { Lettonie } & { }^{*} \text { République tchèque } \\ { }^{*} \text { Bulgarie } & { }^{*} \text { Lituanie } & { }^{*} \text { Roumanie } \\ { }^{*} \text { Estonie } & { }^{*} \text { Pologne } & { }^{*} \text { Russie } \\ { }^{*} \text { Hongrie } & { }^{*} \text { République slovaque }\end{array}$

Pays et territoires en développement plus avancés

$\begin{array}{lll}\text { + Antilles néerlandaises } & \text { Emirats arabes unis } & \text { Mariannes du Nord } \\ \text { + Aruba } & \text { + Falkland, îles } & \text { + Nouvelle-Calédonie } \\ \text { Bahamas } & \text { +Gibraltar } & \text { + Polynésie française } \\ \text { + Bermudes } & \text { + Hong-Kong, Chine } & \text { Oatar } \\ \text { Brunei } & \text { Israël } & \text { Singapour } \\ \text { + Caïmans, îles } & \text { Koweït } & \text { Taipei chinois } \\ \text { Corée, Rép. } & \text { Lybie } & \text { + Vierges, îles (RU) } \\ \text { Chypre } & + \text { Macao } & \end{array}$

Remarque: Selon la politique adoptée par le CAD en 1993, la liste des bénéficiaires de l'aide établie par le CAD est composé de deux parties. Les examens périodiques, suivant des critères établis, peuvent conduire au fait que certains pays bénéficiaires soient transférés d'une partie à une autre, notamment de la Partie I à la Partie II (voir le rapport Coopération pour le développement, 1996, p. A101).

Source: OCDE, Les dossiers du CAD, Coopération pour le développement, développement international, rapport 1999, 2000, vol. I, p. 284.

www.oecd.org/dac/htm/daclst2000.htm.

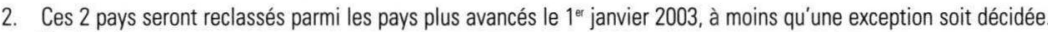

+ Territoires.

* Pays d'Europe centrale et orientale (PECO) / Communauté des Etats indépendants (CEI). 